\title{
Creating presence, currency and connection in digital learning with video blogs
}

\author{
Joanne Elliott, Chie Adachi \\ Deakin University
}

\begin{abstract}
There is a substantial body of work arguing that sense of belonging, connection and interaction is a critical element for students to persist and succeed in learning online. However online students frequently report feeling isolated and disconnected from teachers, peers, and the institution. This paper explores the use of regular, informal video messages to facilitate these connections in a fully online course We argue that such videos can build teacher presence, provide opportunities for sharing feedback, guidance, emerging developments and professional insights, and contribute to a dynamic and engaging learning environment. We share preliminary feedback and reflections on the use of such videos and discuss the next steps in measuring the impact of these videos on student learning and satisfaction.
\end{abstract}

Keywords: student engagement, teacher presence, belonging, feedback, online learners

\section{Introduction}

Developments in digital learning design and practice, and the technologies that facilitate digital learning, offer both advantages and challenges for educators, learning designers and learners themselves. Increasing demand for online learning opportunities, including the impacts of the COVID-19 pandemic, has prompted significant research, and resulting change in practice, into how best to design digital learning to create inclusive, accessible and engaging learning experiences for all students (e.g., Anderson, Annand, \& Wark, 2005; Brunton et al., 2016; Fisher and Baird, 2005; Kuo, Walker, Schroder, \& Belland, 2014; Stone and Springer, 2019). The rising popularity of MOOCs and other short courses designed specifically for adult, online learners has seen an increase in high-quality, high production value and interactive learning materials to facilitate flexible, selfdirected learning experiences. However, students studying online tend to have lower retention and success rates than their on-campus counterparts, and many online learners report feelings of isolation and lack of connection with their university (Department of Education and Training, 2017; Khalil and Ebner, 2014). In order to deliver on the promise of online learning, digital learning experiences must facilitate a sense of connection whilst also promoting flexibility and self-direction.

\section{Designing for Digital Learning}

Online learning was once considered, and designed as, an extension of distance learning, with students navigating repositories of PDFs and lecture recordings, with little to no interaction with teaching staff and peers. However, it is now widely acknowledged that active learning, social learning, teacher presence, and timely, targeted support and feedback are no less important in digital learning than in more traditional, classroom-based learning experiences (Bawa, 2016; Kuo, et al., 2014; Stone and Springer, 2019). Whereas these may occur incidentally and organically in classroom-based learning experiences, they must be intentionally designed for in the online learning environment (Stone, 2017; Stone and Springer, 2019).

A key challenge in digital learning design is achieving balance between the need for flexibility and the need to feel connected to teaching staff, peers, and the institution. Students who study online frequently cite a need for flexibility as a driving factor in choosing online study (Bawa, 2016; Brunton et al., 2016); for example, they may be studying part-time while balancing work and caring commitments or living and studying in a different timezone to the institution delivering the course. Online learning experiences therefore need to be designed to support self-directed learning and enable students to easily access and engage with learning materials at times and in ways that suit their personal circumstances (Kuo, et al., 2014). This self-directed learning is particularly important for adult learners who are studying in order to progress or change careers and wish to be able to tailor their learning experience by exploring some areas of particular interest or relevance in more depth while not 
spending too much time on topics with which they have greater familiarity or experience (Anderson, et al., 2005). Fisher and Baird (2005) propose that online courses should act as "a learning roadmap, [with] the moderator as a guide, offering suggestions and supporting students as they construct the knowledge they are seeking to meet their intrinsic needs." (p. 92).

Fisher and Baird's (2005) description emphasises the importance of the guidance and support of the teacher in helping students succeed in their learning goals. This sense of teacher presence, or connection to teaching staff, is a key factor in student engagement, with "positive, supportive and reciprocal" interactions (Farr-Wharton, Charles, Keast, Woolcott, \& Chamberlain, 2017; p. 5) with teaching staff contributing to increased engagement, motivation, learning and retention (Farr-Wharton, et al., 2017; Feldman, 1989; Kuo, et al., 2014; Ryan and Deci, 2000). Similarly, connections with peers can promote learning through sharing ideas, and receiving feedback to help identify and clarify misconceptions, as well as contributing to a sense of identity as a student and member of a learning community (Anderson, et al., 2005; Knightley, 2007).

Many teachers and students report beliefs that on-campus learning better supports interaction and connection than online courses (Lauver, Drum, Windsor, \& Miller, 2013), which may reflect a prioritisation of 'real-time' connection. Yet digital technologies afford opportunities for asynchronous connection and building teacher presence, supporting interaction and dialogue alongside flexibility (Anderson, et al., 2005; Kuo, et al., 2014). Text-based discussion forums to which students can post and reply to comments, provide opportunities for students to connect with and receive feedback from peers and teachers (Kuo, et al., 2014; Stone and Springer, 2019). Videos featuring teaching staff can also promote teacher presence and create a sense of connection through creating a sense that students know who their teachers are and are able to connect the content presented, comments in discussion forums and feedback on assessment tasks with a face and voice (Stone and Springer, 2019). Interactive quizzes and polls can also help facilitate a sense of connection through the provision of (automated) feedback on student responses. Such interactions help facilitate a 'conversation' between students, teachers and peers, which guides and extends learning (e.g., Laurillard, 2012)

\section{Our Context: Digital Learning, Design and Assessment}

Deakin University's Digital Learning Leadership program, which includes both Masters and Graduate Certificate qualifications, is a fully-online program designed for educators and learning design professionals to develop and extend their capabilities in digital learning. The courses within it are designed to build upon learners' existing skills and experience and create a culture of belonging and peer-sharing. The structure and development of this program has been described in greater detail in Adachi and O'Donnell (2019).

The program's introductory unit, EEE726 Digital Learning, Design and Assessment, is the focus of the intervention described in this paper. This unit is hosted in FutureLearn, an online course provider, specializing in Massive Online Open Courses (MOOCs), with which Deakin has partnered since 2016. The two authors share coordination and teaching of the unit, alternating the 'lead' role across teaching periods. The unit is structured as five two-week modules ('courses' in FutureLearn terminology), with the first two-week module offered as a standalone, free MOOC. The MOOC component of the unit attracts a large, global and diverse learner cohort with a wide range of skillsets, areas and degrees of experience but a common interest in digital learning; these learners participate in the two-week MOOC alongside the Deakin students who continue on to complete the additional four modules and associated assessment tasks.

The unit content, including that of the MOOC component, consists of purposefully-designed, high-quality, highproduction-value learning materials including text, video, interactive quizzes and polls, and embedded discussion forums hosted both in the FutureLearn platform and in additional platforms such as Padlet. These are supplemented, for learners undertaking the full unit, with fortnightly, interactive online seminars. For sustainability, many of the learning materials, specifically the video content, are designed to be used across multiple teaching periods. As such, the teaching team avoid including references to specific time periods or events which would date the videos.

A variety of methods are used to create a sense of teaching presence and to facilitate a sense of connection, both between students and with the teaching team. The teaching team feature in videos throughout the course, speaking directly to camera while presenting content and sharing their perspectives and experiences in digital learning. Digital storytelling techniques are employed in these videos, and throughout the unit, to break down concepts and theories into comprehensible 'chunks' and bring them to life by linking them with practice (Robin, 2008). Another example of the use of digital storytelling and the promotion of teacher presence are the 'Behind the scenes' stories, incorporated throughout the course. In these short blocks of text, the team also share their 
own experience and practice in digital learning to link theory and practice, and scaffold students' own integration of new concepts into their own learning design practice. These stories also model for students how they can share and reflect on their own stories and experiences of digital learning in response to the 'tasks' in each discussion forum. The teaching team are active in the discussion forums, 'liking' and responding to student comments, linking threads and providing prompts to extend the discussions. The fortnightly online seminars provide additional, synchronous opportunities for students to connect with the teaching team, and each other.

The discussion forums and webinars also serve as an opportunity to provide feedback on students' understanding and integration of the concepts covered in the unit into their practice. This feedback supplements the more formal feedback provided on assessment tasks. Engaging with feedback and in critical reflection are promoted throughout the unit as key tenets of digital learning practice. Peer review and feedback is incorporated into one of the assessment tasks, with students reviewing and providing feedback on each other's drafts and reflecting on both the peer feedback process and the feedback received in their final submission. Reflective prompts are provided as regular intervals throughout the course, both to encourage students to engage in critical reflection on their practice and to scaffold the assessment tasks.

\section{Challenges with Building Teacher Presence and Timely Engagement}

The nature of the learning design and the FutureLearn platform pose some challenges for the teaching team, related to balancing the sustainability and currency of learning materials, and managing the discussion forums. The use of high-production-value videos, graphics, and interactive activities such as quizzes and polls, means that these materials, which focus on key concepts and ideas, have been intentionally designed to be reused across several teaching periods. While text content is reviewed and updated each teaching period, all learning materials are released to students at the beginning of trimester, to support flexibility in their study schedule. This means that all materials are prepared ahead of the trimester, and the teaching team have little opportunity to update these throughout trimester. Learning practitioners operate in a rapidly-changing environment, particularly through the COVID-19 pandemic, and being able to see immediate relevance of unit content to their work, including the reflection of current events, increases motivation and engagement (Fisher and Baird, 2005). As a result, the teaching team incorporate current events and emerging trends in digital learning via the online seminars and discussion forums. Additionally, one teacher is featured much more extensively in the videos embedded throughout the unit, which can lead to an imbalance in the visibility and presence of the two members of the teaching team. The high-production-value nature of the videos also means that, although efforts are made to showcase the personality of the teachers, these videos show students a 'studio' version of their teachers, with bloopers and stumbles edited out.

Discussion forums are embedded on each page of the course, linked to a task or discussion prompt. While this enables students to discuss their learning with their peers and the teaching team at the point of learning, the sheer number of forums means that students may not revisit all forums, instead returning only to those in which they are engaged in an ongoing discussion. While FutureLearn allows users to tag other users in their comments, this is limited to those users already participating in the discussion thread; users who have posted, or participated in, a different thread on the same forum cannot be tagged. This makes it difficult for the teaching team to draw students' attention back to particular discussions and to ensure that students see posts connecting their ideas to those expressed by other students. Responding to individual posts can also be time-consuming for teaching staff.

We explore how informal, weekly videos by teaching staff might be used to facilitate connection and presence, by introducing teachers as individuals, providing timely feedback and guidance through the unit.

\section{Using Video Blogs to Promote Teacher Presence, Connection and Currency}

To address the challenges detailed in the previous section, the teaching team introduced weekly video blogs posted to the unit homepage each Monday morning. In the videos, the teachers reflected on the content covered in the previous week, incorporating key themes raised in the discussion forums and seminars, and highlighting connections between posts by different students and with concepts covered or upcoming. They also outlined key concepts, ideas or events (e.g., seminars or assessment deadlines) for the coming week, and provided tips and guidelines to help students progress through the content and enhance their capabilities as self-regulated learners (e.g., Nicol and Macfarlane-Dick, 2006). For example:

One of the things that I mentioned in the last webinar before the break is that it seems like you guys are getting good at sharing your reflection through the 'Your task' or conversation area, and 
you're doing that deeply within yourself. The other thing I'd like you to consider and start doing more of is to engage with others to do these kinds of reflections. So not just individual comment after comment, which is a good thing to do in and of its own right, but also start thinking about how you might respond to other people's comments and do deeper reflection through the involvement of others.

The videos also provided an opportunity to answer common questions, or provide generalised feedback, for example on assessments. Finally, the teachers shared relevant external events, new publications and emerging trends or observations about digital learning. This information emphasised the links between unit content and students' (current or desired) professional context, providing suggestions for how students might build their professional networks and knowledge specific to areas of interest (e.g., Bridgstock, 2016).

The videos were intentionally created with an informal feel to allow students to get a better sense of who the teaching team were, as individuals and as digital learning practitioners themselves. As previously noted, the prerecorded high-production value 'content' videos embedded throughout the unit show a 'refined' version of the teaching staff; the videos are scripted and created in a recording studio, with errors and stumbles edited out. The weekly video blogs however were filmed using mobile phones or Zoom, and involved minimal, if any, editing. They were not scripted, and stumbles or bloopers were not edited out. In one video, for example, the makeshift tripod holding the mobile phone collapsed, resulting in a few seconds' view of the ceiling amidst much laughter from the educator as she righted the camera and resumed her train of thought. In essence, they featured teachers as individuals, going about their daily work lives. The weekly videos also provided further opportunities for students to 'get to know' the first author, who was featured less frequently in the 'content' videos.

While the pre-recorded videos focused on introducing or explaining particular concepts of theories, the weekly videos provided insights into how the teaching team think and act as digital learning practitioners and helped induct students into the disciplinary culture and ways of working (e.g., Mahoney, Macfarlane, \& Ajjawi, 2019). One aspect of the videos that is specific to this disciplinary context was the ability to, as it was described in one video, 'be so meta about what we're doing and how we're doing digital learning.' The students in the unit are, for the most part, educators and learning design professionals themselves, and their feedback on the unit, both formal and informal, frequently relates to how the teaching team enact and integrate concepts and theories into their practice throughout the unit. The weekly videos provided an opportunity for the teaching team to highlight particular aspects of the unit design and explain those design choices, with links to the theories being explored in the unit.

\section{Preliminary Feedback}

Evaluation of the impact of the weekly videos is underway. Preliminary feedback indicates that students found the videos valuable, engaging, and enjoyable. Specifically, students referred to the videos as a useful source of feedback, indicating that the nature of the video made the feedback more accessible and helped them identify key themes in discussions. Students also referred to the sense of connection with teachers created by the videos. While the introduction of the weekly video blogs did create some challenges for the teachers, namely the need to get comfortable with 'warts and all' recordings of themselves and the additional time commitment, these were minimal and outweighed by the perceived benefit in terms of connections with students.

\section{Conclusions and Next Steps}

Teacher presence promotes student engagement and learning through a sense of connection and belonging, and opportunities for feedback and guidance (Stone and Springer, 2019). The weekly video blogs provided an opportunity to build teacher presence and provide feedback to guide the learning process, while creating opportunities to get to know the teaching team as individuals, share in emerging developments and gain insights into disciplinary cultures and ways of working. Preliminary feedback indicates students viewed the videos as a positive and valuable addition to the learning experience. While the small cohort size (usually less than 15 students) presents limitations in terms of evaluating impact, particularly in terms of student success and retention, evaluation will focus on impacts on student perceptions of feedback, sense of connection and belonging and overall satisfaction. 


\section{References}

Adachi, C. \& O'Donnell, M. (2019). Degree Design Thinking: Integrated design frameworks for emerging online degrees in higher education. In Y. W. Chew, K. M. Chan, and A. Alphonso (Eds.), Personalised Learning. Diverse Goals. One Heart. The Proceedings of ASCILITE 2019. Singapore, 349-353. https://2019conference.ascilite.org/assets/proceedings/ASCILITE-2019-Proceedings-Final.pdf

Anderson, T., Annand, D., \& Wark, N. (2005). The search for learning community in learner paced distance education: Or, 'Having your cake and eating it, too! Australasian Journal of Educational Technology, 21(2), 224-241. https://doi.org/10.14742/ajet.1336

Bawa, P. (2016). Retention in Online Courses: Exploring Issues and Solutions-A Literature Review. SAGE Open, 6(1). https://doi.org/10.1177/2158244015621777

Bridgstock, R. (2016). Graduate employability 2.0: Social networks for learning, career development and innovation in the digital age. http://www.graduateemployability2-0.com/resources/articles/

Brunton, J., Brown, M., Cleary, A., Costello, E., Delaney, L., Fox, S., . . Ward, J. (2016). Lost in Transition: A Report on Enabling Success for Flexible Learners. Dublin, Ireland: Dublin City University.

Department of Education and Training. (2017). Improving retention, completion and success in higher education. Department of Education and Training. https://docs.education.gov.au/documents/discussionpaper-improving-completion-retention-and-success-higher-education

Farr-Wharton, B., Charles, M. B., Keast, R., Woolcott, G., \& Chamberlain, D. (2017). Why lecturers still matter: the impact of lecturer-student exchange on student engagement and intention to leave university prematurely. Higher Education. https://doi.org/10.1007/s10734-017-0190-5

Feldman, K. A. (1989). The Association between Student Ratings of Specific Instructional Dimensions and Student Achievement: Refining and Extending the Synthesis of Data from Multisection Validity Studies. Research in Higher Education, 30(6), 583-645. https://doi.org/10.1007/BF00992392

Fisher, M., \& Baird, D. E. (2005). Online learning design that fosters student support, self-regulation, and retention. Campus-Wide Information Systems, 22(2), 88-107. https://doi.org/10.1108/10650740510587100

Khalil, H., \& Ebner, M. (2014) MOOCs Completion Rates and Possible Methods to Improve Retention - A Literature Review. EdMedia + Innovate Learning 2014, Tampere, Finland. https://www.learntechlib.org/p/147656

Knightley, W. M. (2007). Adult learners online: students' experiences of learning online. Australian Journal of Adult Learning, 47(2), 264-287. https://files.eric.ed.gov/fulltext/EJ797581.pdf

Kuo, Y.-C., Walker, A. E., Schroder, K. E. E., \& Belland, B. R. (2014). Interaction, Internet self-efficacy, and self-regulated learning as predictors of student satisfaction in online education courses. The Internet and Higher Education, 20, 35-50. https://doi.org/10.1016/j.iheduc.2013.10.001

Laurillard, D. (2012). Teaching As a Design Science: Building Pedagogical Patterns for Learning and Technology. London: Routledge.

Lauver, K. J., Drum, D. M., Windsor, J. M., \& Miller, S. M. (2013). Preference of education mode. Journal of Applied Research in Higher Education, 5(1), 113-128. https://doi.org/10.1108/17581181311310315

Mahoney, P., Macfarlane, S., \& Ajjawi, R. (2019). A qualitative synthesis of video feedback in higher education. Teaching in Higher Education, 24(2), 157-179. https://doi.org/10.1080/13562517.2018.1471457

Nicol, D. J., \& Macfarlane-Dick, D. (2006). Formative assessment and self-regulated learning: a model and seven principles of good feedback practice. Studies in Higher Education, 31(2), 199-218. https://doi.org/10.1080/03075070600572090

Robin, B. R. (2008). Digital Storytelling: A Powerful Technology Tool for the 21st Century Classroom. Theory Into Practice, 47(3), 220-228. https://doi.org/10.1080/00405840802153916

Ryan, R. M., \& Deci, E. L. (2000). Intrinsic and Extrinsic Motivations: Classic Definitions and New Directions. Contemporary Educational Psychology, 25(1), 54-67. https://doi.org/10.1006/ceps.1999.1020

Stone, C. (2017). Opportunity through Online Learning: Improving student access, participation and success in higher education. Perth: The National Centre for Student Equity in Higher Education (NCSEHE), Curtin University.

Stone, C., \& Springer, M. (2019). Interactivity, connectedness and "teacher-presence": Engaging and retaining students online. Australian Journal of Adult Learning, 59(2), 146-169.

https://search.informit.org/doi/10.3316/aeipt.224048 
Elliott, J., and Adachi, C. (2021). Creating presence, currency and connection in digital learning with video blogs. In Gregory, S., Warburton, S., \& Schier, M. (Eds.), Back to the Future - ASCILITE '21. Proceedings ASCILITE 2021 in Armidale (pp. 155-160). https://doi.org/10.14742/ascilite2021.0121

Note: All published papers are refereed, having undergone a double-blind peer-review process.

The author(s) assign a Creative Commons by attribution licence enabling others to distribute, remix, tweak, and build upon their work, even commercially, as long as credit is given to the author(s) for the original creation.

(C) Elliott, J., \& Adachi, C. 2021 